\title{
Fulminant hepatic failure in autoimmune polyendocrine syndrome type-I
}

\author{
${ }^{1} \mathrm{R}$ Sinha, ${ }^{2} \mathrm{AR}$ Chapman, ${ }^{3} \mathrm{GT}$ Reid, ${ }^{4} \mathrm{PC}$ Hayes \\ ${ }^{1}$ Clinical Research Fellow, Scottish Liver Transplant Unit, Royal Infirmary Edinburgh, Edinburgh; ${ }^{2}$ Core medical trainee, Royal Infirmary of \\ Edinburgh; ${ }^{3}$ Specialist registrar in histopathology, Royal Infirmary of Edinburgh; ${ }^{4}$ Professor of hepatology, Royal Infirmary of Edinburgh, \\ Edinburgh, UK.
}

\begin{abstract}
Fulminant hepatic failure is liver disease that causes encephalopathy within 8 weeks of onset of symptoms or within 2 weeks of onset of jaundice in a patient without prior evidence of liver disease. Autoimmune polyendocrine syndrome type-I is an autoimmune autosomal-recessive condition causing parathyroid and adrenal insufficiency, alopecia, chronic mucocutaneous candidiasis, ectodermal dystrophy and, rarely, hepatitis. Although the liver can be affected as a consequence of the autoimmune process, the spectrum of disease activity is varied.Autoimmune hepatitis develops in 10-20\% of patients and successful liver transplantation has been reported in pediatric patients who failed immunosuppressive treatment. We report fulminant hepatic failure in an adult patient with autoimmune polyendocrine syndrome type-I who responded to medical treatment and did not require liver transplantation. We highlight the diagnostic scoring system for autoimmune hepatitis and the referral criteria for liver transplantation in fulminant hepatic failure.
\end{abstract}

KEYWORDS autoimmune polyendocrine syndrome type-I, autoimmune hepatitis, fulminant hepatic failure, liver transplantation

DECLARATION OF INTERESTS No conflict of interest declared.

\author{
Correspondence to R Sinha \\ Scottish Liver Transplant Unit \\ Royal Infirmary of Edinburgh \\ Little France \\ Edinburgh EHI6 4SA \\ UK
}

e-mail rohits78@gmail.com

\section{INTRODUCTION}

Autoimmune polyendocrine syndrome-I (APS-I) is an autoimmune autosomal-recessive condition causing parathyroid and adrenal insufficiency, alopecia, chronic mucocutaneous candidiasis, ectodermal dystrophy and, rarely, hepatitis. This condition is also known as autoimmune polyendocrinopathy candidiasisectodermal dystrophy (APECED), Whitaker's syndrome or Blizzard's syndrome. The syndrome was first described by Neufeld and Blizzard' in the 1960s as a rare syndrome presenting in childhood. We describe an unusual and aggressive autoimmune hepatitis, a rare presentation of APS-I syndrome in a young woman, causing hyperacute fulminant hepatic failure (FHF), i.e. liver disease that causes encephalopathy within 8 weeks of onset of symptoms or within 2 weeks of onset of jaundice in a patient without prior evidence of liver disease. ${ }^{2}$ This case highlights the importance of a multi-system approach to acute liver failure and illustrates the contribution of aggressive medical management in avoiding the need for liver transplantation. ${ }^{3}$

\section{CASE REPORT}

A 23-year-old woman presented to a local hospital with a 4-day history of worsening jaundice. She was transferred to the tertiary liver unit in Edinburgh with
FHF. At the time of transfer, the patient had developed grade II encephalopathy with agitation and restlessness with a Glasgow Coma Scale of 10 (E3V4M5). There was no history of a preceding intercurrent illness, nor had any new hepatotoxic medications been commenced. Collateral history confirmed episodic alcohol consumption on weekends, amounting to less than 3 units per day, and no paracetamol, over-the-counter drug or herbal medication use.

She had previously been diagnosed with APS-I, (Addison's disease, hypoparathyroidism, alopecia and pernicious anaemia) at the age of four. She had been admitted several times for refractory hypocalcaemia resulting in tetany, despite the use of high dose calcium and vitamin D supplements. She had recently started taking a recombinant parathyroid hormone analogue (teriparatide) for resistant hypoparathyroidism. At presentation the patient was taking the following medications: calcitriol $2 \mathrm{mcg}$ once daily, teriparatide (recombinant parathyroid hormone analogue) $20 \mathrm{mcg}$ once daily, two Adcal D3 tablets (3000 mg calcium + 800 iU cholecalciferol) daily, fludrocortisone $250 \mathrm{mcg}$ daily, hydrocortisone $30 \mathrm{mg}$ daily in divided dose, Slow-K $1800 \mathrm{mg}$ daily in divided doses and magnesium glycerophosphate $8 \mathrm{mmol}$ daily in divided doses. Her endocrine replacement therapies were regularly monitored by the local endocrinology team. There was no concern regarding adherence as 
TABLE I King's College Hospital criteria: assessment of acute liver failure for orthotopic liver transplantation

\begin{tabular}{|c|c|}
\hline Category & Criteria \\
\hline 1 & $\begin{array}{l}\text { Aetiology: Paracetamol poisoning: } \\
\mathrm{pH}<7.25 \text { more than } 24 \text { hours after overdose } \\
\text { and after fluid resuscitation. }\end{array}$ \\
\hline 2 & $\begin{array}{l}\text { Aetiology: Paracetamol poisoning: } \\
\text { Co-existing prothrombin time }>100 \text { seconds } \\
\text { or INR }>6.5 \text {, and serum creatinine }>300 \\
\mu \text { mol// or anuria, and grade } 3-4 \\
\text { encephalopathy. }\end{array}$ \\
\hline 3 & $\begin{array}{l}\text { Aetiology: Paracetamol poisoning: } \\
\text { Serum lactate more than } 24 \text { hours after } \\
\text { overdose }>3.5 \mathrm{mmol} / \mathrm{l} \text { on admission or }>3.0 \\
\mathrm{mmol} / \mathrm{l} \text { after fluid resuscitation. }\end{array}$ \\
\hline 4 & $\begin{array}{l}\text { Aetiology: Paracetamol poisoning: } \\
\text { Two of the three criteria from category } 2 \\
\text { with clinical evidence of deterioration (e.g. } \\
\text { increased intracranial pressure, } \mathrm{F}_{i} \mathrm{O}_{2}>50 \% \text {, } \\
\text { increasing inotrope requirements) in the } \\
\text { absence of clinical sepsis. }\end{array}$ \\
\hline 5 & $\begin{array}{l}\text { Aetiology: Seronegative hepatitis, hepatitis A, } \\
\text { hepatitis B or an idiosyncratic drug reaction. } \\
\text { Prothrombin time }>100 \text { seconds or INR }>6.5 \text {, } \\
\text { and any grade of encephalopathy. }\end{array}$ \\
\hline 6 & $\begin{array}{l}\text { Aetiology: Seronegative hepatitis, hepatitis A, } \\
\text { hepatitis B or an idiosyncratic drug reaction. } \\
\text { Any grade of encephalopathy and any three } \\
\text { from the following: unfavourable aetiology } \\
\text { (idiosyncratic drug reaction, seronegative } \\
\text { hepatitis), age }>40 \text { years, jaundice to } \\
\text { encephalopathy time }>7 \text { days, serum bilirubin } \\
>300 \mu \mathrm{mol} / \text { /, prothrombin time }>50 \text { seconds } \\
\text { or INR }>3.5\end{array}$ \\
\hline 7 & $\begin{array}{l}\text { Aetiology: Acute presentation of Wilson's } \\
\text { disease or Budd-Chiari syndrome.A } \\
\text { combination of coagulopathy and any grade of } \\
\text { encephalopathy. }\end{array}$ \\
\hline
\end{tabular}

this condition was diagnosed at an early age and episodes of accidental missed doses resulted in symptoms such as tetany requiring hospital admission. There was no family history of liver disease. She had no known liver disease and her previous liver biochemistry was unremarkable. She was the younger of two children of non-consanguineous parents.

On examination, the patient was jaundiced and encephalopathic with asterixis. She had marked alopecia but there were no stigmata of chronic liver disease. Abdominal examination was unremarkable with no evidence of ascites. There was no enamel hypoplasia or nail dystrophy. She had FHF and, as per King's College Hospital criteria (Table I), she fulfilled two criteria in category 6 (encephalopathy and bilirubin $>300 \mu \mathrm{mol} / \mathrm{l})$. Initial investigation results are shown in Table 2. Her pre-treatment aggregate score

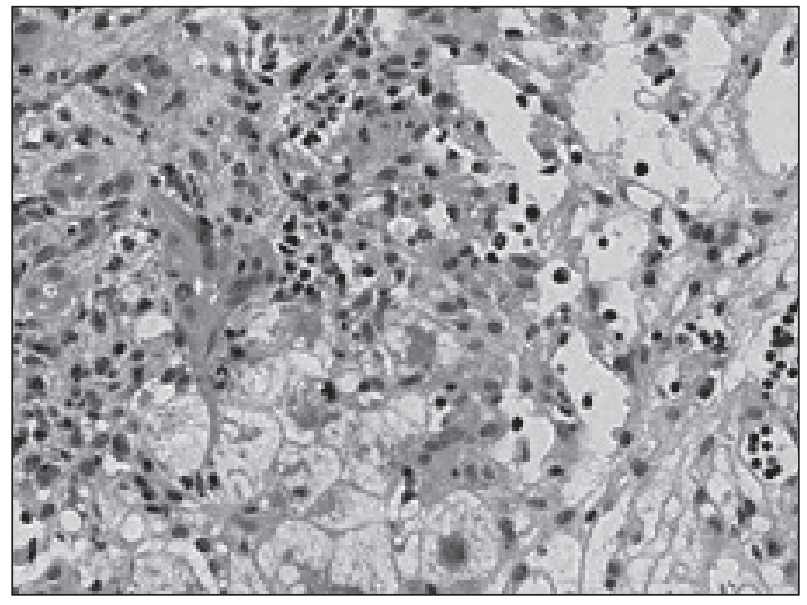

FIGURE I Initial liver biopsy, showing collapse, inflammation with some interface hepatitis consisting of lymphocytes and some plasma cells, but no eosinophils, swelling and degeneration of hepatocytes with some Mallory bodies, some fibrosis

on the International Autoimmune Hepatitis scoring system $^{4}$ (Table 3 ) was I8.

In view of the syndrome and its association of mucocutaneous candidiasis - in the context of elevated white cell and differentials - a gastroscopy was performed which showed some evidence of reflux oesophagitis but no candidiasis. Although there was no evidence of mucocutaneous fungal infection, she received prophylactic anti-fungals as part of the FHF management protocol. Computed tomography of the brain found no intracranial causes of reduced conscious level and computed tomography of the abdomen found no evidence of disseminated malignancy. The patient required intubation to facilitate transjugular biopsy of the liver, with histology shown in Figure I.

\section{HISTOLOGY}

Histological examination of a liver biopsy specimen (Figure I) showed significant fibrosis and widespread destruction of hepatic parenchyma, approximately $40 \%$ by area. There were areas of collapse and hepatocyte loss, and in areas of surviving parenchyma there were numerous lymphocytes present and occasional plasma cells. No eosinophils were noted. Appearances were therefore suggestive of immunologically mediated, widespread destruction of liver parenchyma, consistent with acute autoimmune hepatitis. Having not fully met the criteria for transplantation, she was not listed for urgent liver transplantation and was instead treated with pulsed methylprednisolone (based on body weight) given the strong suspicion of autoimmune hepatitis shown by the liver biopsy.

She remained intubated because of encephalopathy and continued to be managed in the ITU. Liver parameters were very slow to resolve and she was 
R Sinha, AR Chapman, GT Reid et al.

TABLE 2 Laboratory investigation on admission

\begin{tabular}{|c|c|c|}
\hline Laboratory investigations & Result & Normal range \\
\hline Haemoglobin & $137 \mathrm{~g} / \mathrm{L}$ & $115-160 \mathrm{~g} / \mathrm{L}$ \\
\hline White cell count & $12.1 \times 10^{9} / \mathrm{L}$ & $4.0-11.0 \times 10^{9} / \mathrm{L}$ \\
\hline Platelet count & $266 \times 10^{9} / \mathrm{L}$ & $150-400 \times 10^{9} / \mathrm{L}$ \\
\hline Prothrombin time & 24 secs & $11-14$ secs \\
\hline INR & 2.2 & 1.0 \\
\hline Sodium & $139 \mathrm{mmol} / \mathrm{L}$ & $135-145 \mathrm{mmol} / \mathrm{L}$ \\
\hline Potassium & $2.7 \mathrm{mmol} / \mathrm{L}$ & $3.6-5.0 \mathrm{mmol} / \mathrm{L}$ \\
\hline Urea & $2.9 \mathrm{mmol} / \mathrm{L}$ & $2.5-6.6 \mathrm{mmol} / \mathrm{L}$ \\
\hline Creatinine & $54 \mu \mathrm{mol} / \mathrm{L}$ & $60-120 \mu \mathrm{mol} / \mathrm{L}$ \\
\hline Bilirubin & $363 \mu \mathrm{mol} / \mathrm{L}$ & $3-21 \mu \mathrm{mol} / \mathrm{L}$ \\
\hline Alanine transaminase & III5 U/L & $10-50 \mathrm{U} / \mathrm{L}$ \\
\hline Aspartate transaminase & $1922 \mathrm{U} / \mathrm{L}$ & $10-30 \mathrm{U} / \mathrm{L}$ \\
\hline Alkaline phosphatase & $784 \mathrm{U} / \mathrm{L}$ & $40-125 \mathrm{U} / \mathrm{L}$ \\
\hline Albumin & $32 \mathrm{~g} / \mathrm{L}$ & $30-45 \mathrm{~g} / \mathrm{L}$ \\
\hline Glucose & $3.7 \mathrm{mmol} / \mathrm{L}$ & $3.0-6.0 \mathrm{mmol} / \mathrm{L}$ \\
\hline Caeruloplasmin & $0.28 \mathrm{~g} / \mathrm{L}$ & $0.16-0.47 \mathrm{~g} / \mathrm{L}$ \\
\hline Alpha-I antitrypsin & $1.66 \mathrm{~g} / \mathrm{L}$ & $1.12 .1 \mathrm{~g} / \mathrm{L}$ \\
\hline Ferritin & $131 \mu g / L$ & $15-200 \mu \mathrm{g} / \mathrm{L}$ \\
\hline $\lg G$ & $21.5 \mathrm{~g} / \mathrm{L}$ & $6-15 \mathrm{~g} / \mathrm{L}$ \\
\hline $\lg M$ & $5.3 \mathrm{~g} / \mathrm{L}$ & $0.35-2.9 \mathrm{~g} / \mathrm{L}$ \\
\hline ANA & POSITIVE (I/I60) & \\
\hline Gastric parietal cell antibody & POSITIVE & \\
\hline Anti-mitochondial antibody & NEGATIVE & \\
\hline Anti ds-DNA & NEGATIVE & \\
\hline Anti smooth-muscle antibody & NEGATIVE & \\
\hline Anti liver kidney microsomal antibodies & NEGATIVE & \\
\hline Viral serology hepatitis A, B, C, D and E & NEGATIVE & \\
\hline Viral serology EBV, CMV, HIV & NEGATIVE & \\
\hline
\end{tabular}

No paraprotein detected on electrophoresis.

extubated on day II. Subsequently she was switched to intravenous hydrocortisone followed by oral prednisolone upon restoration of consciousness.

During her post intensive care recovery, she had profound bilateral leg weakness, right foot drop and significantly deranged electrolytes. She remained deeply jaundiced (bilirubin $>300 \mu \mathrm{mol} / \mathrm{L}$ ) but gradual improvements in alanine transaminase, prothrombin time and albumin were noted, with no evidence of encephalopathy.

On day 28 she had a percutaneous liver biopsy for persistent hyperbilirubinemia and fluctuation in transaminses, despite preserved synthetic function. The introduction of a second immunosuppressive agent was considered but not commenced pending results. The biopsy was reassuring (Figure 2), with a reported disappearance of inflammatory activity, together with some collapse and necrosis in keeping

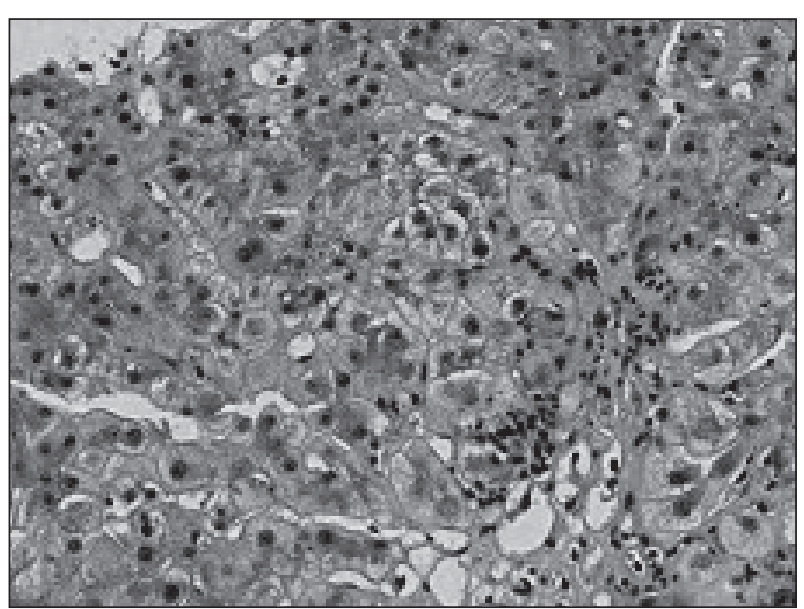

FIGURE 2 Follow-up biopsy, showing severe ductular cholestasis, hepatocellular cholestasis, cholestatic injury and mild fibrous expansion of portal tracts with porto-portal fibrosis and a ductular reaction 
with abnormal regenerative activity. She was discharged to a local tertiary-care hospital on dual immunosuppressive therapy of steroids and azathioprine. Her liver biochemical tests have normalised and she is currently on dual immunosuppressive agents, under regular medical review at a specialist hepatology clinic.

\section{DISCUSSION}

Fulminant hepatic failure or acute liver failure is characterised by hepatocellular necrosis resulting in impaired hepatic synthetic function in the absence of pre-existing liver disease. Based on the development of encephalopathy from the onset of jaundice, acute liver failure can be classified into the O'Grady system of hyper-acute (less than 7 days), acute ( $1-4$ weeks) and sub-acute (4-12weeks), or the Bernau system of fulminant (0-2weeks) or sub-fulminant (2-12 weeks). ${ }^{5}$ Survival is as low as $15 \%^{6}$ without liver transplantation and is inversely related to the interval between jaundice to onset of encephalopathy. The most common cause of acute liver failure is paracetamol toxicity, followed by viral hepatitis.

It is important to establish the cause of FHF in order to initiate appropriate treatment, to prognosticate and to guide consideration of liver transplantation. A liver screen comprising of a panel of blood investigation for viral hepatitis (A, B, C, D, E, CMV, EBV and HIV), autoantibodies, serum immunoglobins, caeruloplasmin, alpha-I antitrypsin, ferritin and alpha-fetoprotein forms part of the initial assessment for any acute liver injury presentation. A trans-abdominal ultrasound provides a further quick assessment in excluding focal hepatic lesions or underlying chronicity. Occasionally, computed tomography of the chest, abdomen and pelvis may be required if the suspicion of malignancy is high in order to search for liver infiltration or focal malignancy elsewhere.

Severe autoimmune hepatitis causing FHF is rare. Diagnosis is based on excluding other causes, on the presence of gamma globulin levels $>20 \mathrm{~g} / \mathrm{L}$, significant titers of autoantibodies, and the presence of a marked lymphoplasmocytic infiltrate on a histological examination of liver biopsy specimens. ${ }^{4}$

Autoimmune polyendocrine syndrome-I is a rare autosomal-recessive condition associated with mutations of the AIRE (Autoimmune Regulator) gene on chromosome $21,{ }^{7}$ which is involved in central and peripheral immune tolerance mechanisms. Although rare, the prevalence is relatively higher in Iranian Jewish, Sardinian, Norwegian and Finnish populations. Mutations cause loss of central immune tolerance; failure to eliminate autoreactive $T$ cells in the thymus, and their escape to the periphery. These patients are susceptible to mucocutaneous candidiasis and multiple endocrine and non-endocrine autoimmune diseases.
TABLE 3 International Autoimmune Hepatitis score in adults

\begin{tabular}{|l|l|c|}
\hline Category & \multicolumn{1}{|c|}{ Factor } & Score \\
\hline Gender & Female & +2 \\
\hline \multirow{2}{*}{$\begin{array}{l}\text { AlkP:AST (or } \\
\text { ALT) ratio }\end{array}$} & $>3$ & -2 \\
\cline { 2 - 3 } & $<1.5$ & +2 \\
\cline { 2 - 3 } & $>2.0$ & +3 \\
\hline \multirow{2}{*}{$\begin{array}{l}\text { (above nobulin of IgG } \\
\text { limit) }\end{array}$} & $1.5-2.0$ & +2 \\
\cline { 2 - 3 } & $1.0-1.5$ & +1 \\
\cline { 2 - 3 } $\begin{array}{l}\text { ANA, SMA or } \\
\text { anti-LKMI titres }\end{array}$ & $>1.0$ & +3 \\
\cline { 2 - 3 } & $\mathrm{I}: 80$ & +2 \\
\cline { 2 - 3 } & $\mathrm{I}: 40$ & +1 \\
\cline { 2 - 3 } & $<1: 40$ & -4 \\
\hline AMA & Positive & -3 \\
\hline \multirow{2}{*}{ Viral } & Post & +3 \\
\hline
\end{tabular}

\begin{tabular}{|c|c|c|}
\hline AMA & Positive & -4 \\
\hline \multirow[t]{2}{*}{ Viral markers } & Positive & -3 \\
\hline & Negative & +3 \\
\hline \multirow{2}{*}{$\begin{array}{l}\text { Hepatotoxic } \\
\text { drugs }\end{array}$} & Yes & -4 \\
\hline & No & +1 \\
\hline \multirow[t]{2}{*}{ Alcohol } & $<25$ g/day & +2 \\
\hline & $>60$ g/day & -2 \\
\hline $\begin{array}{l}\text { Concurrent } \\
\text { immune disease }\end{array}$ & $\begin{array}{l}\text { Any non-hepatic disease of } \\
\text { immune nature }\end{array}$ & +2 \\
\hline \multirow{3}{*}{$\begin{array}{l}\text { Other } \\
\text { autoantibodies* }\end{array}$} & Anti-SLA/LP,actin,LCI,pANCA & +2 \\
\hline & Interface hepatitis & +3 \\
\hline & Plasma cells & +1 \\
\hline \multirow{4}{*}{$\begin{array}{l}\text { Histologic } \\
\text { features }\end{array}$} & Rosettes & +1 \\
\hline & None of above & -1 \\
\hline & Biliary changes & -3 \\
\hline & Atypical features & -3 \\
\hline HLA & DR3 or DR4 & +1 \\
\hline \multirow{2}{*}{$\begin{array}{l}\text { Treatment } \\
\text { response }\end{array}$} & Remission alone & +2 \\
\hline & Remission relapse & +3 \\
\hline \multirow[t]{6}{*}{ Total score } & Pre-treatment score & \\
\hline & Definite diagnosis & $>15$ \\
\hline & Probable score & $10-15$ \\
\hline & Post-treatment & \\
\hline & Definite diagnosis & $>17$ \\
\hline & Probable diagnosis & $12-17$ \\
\hline
\end{tabular}

AlkP, alkaline phosphatase; ALT, alanine aminotransferase; AST, aspartate aminotransferase; IgG, immunoglobulin G; ANA, antinuclear antibody; SMA, smooth muscle antibody; LKMI, liver kidney microsome type I;AMA, anti-mitochondrial antibody; SLA/LP, soluble liver antibody/liver pancreas; LCI, liver cytosol type I; HLA, human leukocyte antigen.Adapted from International Autoimmune Hepatitis Group ${ }^{4}$

The diagnosis is classically based on the combination of any two of the following three major criteria: chronic mucocutaneous candidiasis, hypoparathyroidism, and autoimmune primary adrenocortical insufficiency (Addison's disease).The first endocrinopathy to manifest 
is usually hypoparathyroidism followed by Addison's disease. $^{8}$ Other autoimmune processes that may co-exist in APS-I are primary gonadal failure, autoimmune thyroid disease, type I diabetes mellitus, pernicious anaemia, intestinal dysfunction, autoimmune hepatitis of varying severity and alopecia. ${ }^{9}$

To our knowledge this is the first presentation of acute FHF due to autoimmune hepatitis described in an adult with APS-I. The diagnosis of autoimmune hepatitis was confirmed on biopsy and with the use of the criteria of the International Autoimmune Hepatitis Group (Table 3). ${ }^{4}$ Only two orthotopic liver transplantations ${ }^{2,10}$ have been described, both in paediatric patients for acute or chronic liver failure. Of these patients only one survived.

\section{REFERENCES}

I Neufeld M, Maclaren NK, Blizzard RM. Two types of autoimmune Addison's disease associated with different polyglandular autoimmune (PGA) syndromes. Medicine 198I; 60: 355-62.

2 Trey C, Davidson CS. The management of fulminant hepatic disease. Prog Liver Dis 1970; 3: 282-98.

3 Smith D, Stringer M,Wyatt J et al. Orthotopic liver transplantation for acute liver failure secondary to autoimmune hepatitis in a child with autoimmune polyglandular syndrome type. Pediatr Transplant 2002; 6: 166-70.

4 Alvarez F, Berg PA, Bianchi FB et al. International Autoimmune Hepatitis Group Report: review of criteria for diagnosis of autoimmune hepatitis. J Hepatol 1999; 31: 929-38.

5 Bernal W, Wendon J. Acute liver failure. N Engl J Med 20I3; 369: 2525-34. http://dx.doi.org/I0.I056/NEJMra I 208937

6 Gotthardt D, Riediger C,Weiss $\mathrm{KH}$ et al. Fulminant hepatic failure: etiology and indications for liver transplantation. Nephrol Dial Transplant 2007; 22: viii5-viii8.
Our patient was managed with single agent immunosuppression in an intensive care setting, with clinical, biochemical and histological improvement noted over a 4-week period. Due to the low prevalence of this condition, detection of liver involvement may be delayed. If medical therapy is unsuccessful, liver transplantation remains an option. In conclusion, this young woman had a first presentation of FHF on a background of APS-I without evidence of chronicity on liver biopsy and was successfully managed with immunosuppression and supportive therapy. Early recognition of acute liver failure using the King's College Hospital criteria and referral to a tertiary liver unit is key to the outcome. Furthermore, prognosis of FHF is also dependent on etiology, clinical presentation and course, biological status, gender and timing of liver transplantation."

7 The Finnish-German APECED Consortium. An autoimmune disease, APECED, caused by mutations in a novel gene featuring two PHD-type zinc-finger domains. Nat Genet 1997; 17: 399-403.

8 Ahonen P, Myllarniemi S, Sipila I, et al. Clinical variation of autoimmune polyendocrinopathy-candidiasis-ectodermal dystrophy (APECED) in a series of 68 patients. N Engl J Med 1990; 322: 1829-36.

9 Betterle C, Greggio NA,Volpato M. Clinical review 93: autoimmune polyglandular syndrome type I.J Clin Endocrinol Metab 1998; 83: I049-55.

10 Michele TM, Fleckenstein J, Sgrignoli AR et al. Chronic active hepatitis in the type I polyglandular autoimmune syndrome. Postgrad Med J 1994; 70: |28-3|

II Ichai P, Samuel D. Etiology and prognosis of fulminant hepatitis in adults. Liver Transp/ 2008; 14: S67-S79. http://dx.doi.org//0.1002/ It.21612 